NBER WORKING PAPER SERIES

\title{
WHO DID THE ETHANOL TAX CREDIT BENEFIT? AN EVENT ANALYSIS OF SUBSIDY INCIDENCE
}

\author{
David A. Bielen \\ Richard G. Newell \\ William A. Pizer \\ Working Paper 21968 \\ http://www.nber.org/papers/w21968 \\ NATIONAL BUREAU OF ECONOMIC RESEARCH \\ 1050 Massachusetts Avenue \\ Cambridge, MA 02138 \\ February 2016
}

The research described in this paper was supported in part by the Bipartisan Policy Center. The views expressed herein are those of the authors and do not necessarily reflect the views of the National Bureau of Economic Research.

NBER working papers are circulated for discussion and comment purposes. They have not been peerreviewed or been subject to the review by the NBER Board of Directors that accompanies official NBER publications.

(C) 2016 by David A. Bielen, Richard G. Newell, and William A. Pizer. All rights reserved. Short sections of text, not to exceed two paragraphs, may be quoted without explicit permission provided that full credit, including $(\subset$ notice, is given to the source. 
Who Did the Ethanol Tax Credit Benefit? An Event Analysis of Subsidy Incidence David A. Bielen, Richard G. Newell, and William A. Pizer

NBER Working Paper No. 21968

February 2016

JEL No. H22,Q11,Q41,Q42,Q48

\begin{abstract}
$\underline{\text { ABSTRACT }}$
Using commodity futures contract and spot prices, we estimate the incidence of the US ethanol subsidy accruing to corn farmers, ethanol producers, gasoline blenders, and gasoline consumers at expiration in 2011. We find compelling evidence that ethanol producers captured two-thirds of the subsidy, and suggestive evidence that a small portion of this benefit accrued to corn farmers. The remaining one-third appears to have been captured by blenders, as we find no evidence that oil refiners or gasoline consumers captured any part of the subsidy. This paper contributes to understanding of biofuels markets and policy and empirical estimation of economic incidence.
\end{abstract}

David A. Bielen

Duke University

Box 90467

Durham, NC 27708

dabielen@gmail.com

Richard G. Newell

Duke University

Box 90467

Durham, NC 27708

and NBER

richard.newell@duke.edu
William A. Pizer

Sanford School of Public Policy

Duke University

Box 90312

Durham, NC 27708

and NBER

billy.pizer@duke.edu 


\section{Introduction}

"It might cost you more to fill up with gas as early as New Year's Day. If all other variables stay the same, gas prices should be higher since the tax credit oil companies have received to blend ethanol with their petroleum won't be available."

Jeff Scates, Illinois Corn Growers Association President

"As a result, oil companies have been able to set demand and price levels for ethanol, keeping prices low and pocketing much, if not all, of the VEETC as profit."

Natural Resource Defense Council Policy Fact Sheet

"While those who support the program put forth various reasons for their support - that ethanol will reduce greenhouse gases or curb our reliance on foreign oil - in reality, it is merely a wealth transfer program from the general taxpayer to corn producers."

Washington Examiner Op-Ed Piece

The energy sector in the United States is host to a myriad of policies - regulations, taxes, and subsidies — that shift behavior away from a free-market outcome. Such policies are often motivated by the association of different forms of energy use with significant non-market consequences related to the environment and energy reliability. An important question is whether the benefits from these policies exceed the costs, requiring a careful analysis of non-market benefits (National Research Council, 2010).

Often missing from the aggregate benefit-cost analysis are distributional assessments of who pays or, in the case of a subsidy, who benefits. Incidence is not obvious, as burdens and benefits can accrue to both producers and consumers depending on relative elasticities of response, and may be passed up 
and down a particular supply chain. Moreover, for market-based policies, including taxes and subsidies, the distinct consequences for winners and losers can be many times the aggregate net cost or benefit (Burtraw and Palmer, 2008). In many policy debates, it is these consequences for particular stakeholders that help determine both enactment and survival, regardless of the aggregate net benefit analysis. For both equity in its own right and equity's link to acceptance, it is important to consider these distributional effects.

Perhaps nowhere is this more evident than ethanol, which was the object of the single most expensive energy subsidy in recent history, the Volumetric Ethanol Excise Tax Credit (VEETC). ${ }^{1}$ Regardless of one's stance on whether more ethanol is or is not desirable, or whether the subsidy was effective at encouraging more ethanol, advocates claimed the subsidy lowered motor fuel prices for consumers while critics claimed the subsidy simply enriched ethanol producers. Which view does the evidence support? The answer is relevant not only for the subsidy, but also for understanding the market structure underlying an industry that continues to be the subject of considerable policy intervention through the federal Renewable Fuel Standard.

Policy effects are often difficult to measure because the no-policy counterfactual cannot be observed. Further complicating matters, multiple policies often target the same objective, making it difficult to disentangle the effects of any single policy. This is particularly evident in the case of policies that promoted ethanol, where three different policies were in place from 2005, when both ethanol mandates and an effective ban on MTBE as a fuel additive began, until the end of 2011, when the VEETC was ended.

Nonetheless, the sudden end to the VEETC on December $31^{\text {st }}, 2011$, offers a unique opportunity to observe the incremental consequences of a single policy. In particular, at the time of its termination, was the ethanol subsidy benefiting primarily ethanol producers or consumers? Was the value being passed further up or down the supply chain? By comparing prices along the

\footnotetext{
${ }^{1}$ The VEETC accounted for $\$ 5$ billion per year, or roughly one-quarter of all energy related, non-stimulus subsidies in 2007 and 2011 (U.S. Energy Information Administration, 2011).
} 
supply chain immediately before and after the subsidy expired, we can isolate the effect of the subsidy termination holding other influences constant, and thereby determine the subsidy incidence.

The results suggest that most — perhaps two-thirds - of the subsidy accrued to ethanol producers. Moreover, we find suggestive evidence that a small portion (about 5 c per gallon) of the benefits were passed up the supply chain to corn farmers, although data limitations prevent us from making more confident statements on this front. Random variation in prices for petroleum products makes it difficult to estimate the incidence on oil refiners or gasoline consumers precisely, but the point estimates suggest that these stakeholders received very little, if any, benefit from the subsidy. This refutes the notion that the subsidy largely benefited consumers. Based on the evidence, we conclude that the remaining third of the subsidy was likely being captured by fuel blenders at the time the subsidy expired.

In order to estimate the ethanol subsidy incidence, we use several data sources and empirical techniques. When possible, we use one-month calendar spreads constructed from the futures markets for ethanol, corn, and gasoline blendstock (petroleum). These spreads, reflecting expected one-month price changes, provide a means to differentiate sharply between the prices of products that could benefit from the tax credit, and those (produced after expiration) that could not. For commodities without exchange-traded futures markets, specifically finished gasoline, we use standard time-series regression techniques on spot price data to analyze whether the subsidy expiration coincided with a significant change in the gasoline blending margin around the time of expiration.

This paper is organized as follows: Section 2 provides background on the industry structure for gasoline production and biofuels policy in the United States. Section 3 summarizes the related literature on renewable fuel policies and event studies of policy changes. Section 4 lays out the conceptual framework and discusses how the subsidy might manifest in commodity prices. Section 5 presents the empirical approach and model, describes the data, and discusses the results. Section 6 concludes. 


\section{Gasoline and biofuels policy}

Gasoline production in the United States involves the convergence of two supply chains: one for refined petroleum from crude oil and an agricultural supply chain for ethanol from corn. The process can be described by the schematic outlined in Figure 1 and elaborated below (including how certain producers might be connected at the corporate level).

On the agricultural side, production begins on the farm and ends with blending at the fuel terminal. Corn is harvested, and then shipped to ethanol production facilities for processing. ${ }^{2}$ The amount of corn used for fuel production is significant: in 2011, which was the last year for the VEETC, ethanol production accounted for about 40 percent of corn consumption in the United States (Brester, 2012). The other major input to ethanol production is fuel used to generate electricity for the plant, typically natural gas. The major outputs of the production process are ethanol and distillers grains, which can be sold as animal feed. Once production has occurred, the ethanol is shipped, typically via truck or railcar, to fuel terminals to be blended into gasoline.

Meanwhile, on the petroleum side, production begins with extraction of crude oil and other petroleum liquids and, as with ethanol, ends with blending at the fuel terminal. Crude oil is extracted, possibly shipped, and transported via pipeline to refineries. Refiners process crude oil into several different refined petroleum products, including petroleum blendstock, which is a precursor to finished gasoline. Reformulated blendstock for oxygenated blending (RBOB) and conventional blendstock for oxygenated blending (CBOB) are refined products specifically engineered to be blended with an oxygenate, such as ethanol. ${ }^{3}$ These refined petroleum products are then transported, usually via pipeline, to a fuel terminal.

\footnotetext{
${ }^{2}$ Our focus for this paper is restricted to corn-derived ethanol. The use of other, more advanced biofuel feedstocks is, for the most part, in the research or early commercialization phase, but not yet commercially significant.

${ }^{3} \mathrm{RBOB}$ is used in the production of reformulated gasoline, a product blended to burn more cleanly than conventional gasoline (produced from CBOB). The Clean Air Act requires reformulated gasoline to be used in cities with high smog levels, since petroleum combustion contributes to ground-level ozone formation.
} 
Finished gasoline is the product of combining fuel ethanol, an oxygenate, with gasoline blendstock. From a performance standpoint, oxygenate blending increases the octane of the fuel, which serves the dual purpose of preventing engine "knock" in motor vehicles and also creates a cleaner-burning fuel. However, when used in blends higher than about 5 percent, ethanol transitions from a complement to petroleum to a substitute.

Once both products are in storage at the terminal, they are blended in one of two ways. Either both fuels are combined in a designated blending tank, or they are "splash" blended aboard a fuel truck. ${ }^{4}$ The proportion of ethanol in a gallon of finished gasoline can vary: the most common forms are a $10 \%$ ethanol blend (called E10), usable in most passenger cars, and an $85 \%$ blend (E85), which can only be used in certain "flex fuel" vehicles.

The blended fuel, while still at the terminal, is referred to as wholesale finished gasoline. Relative to wholesale gasoline prices, retail gasoline prices also include the costs of transporting the fuel from the terminal to the retail gas station (typically via a fuel truck), incorporation of federal and state fuel taxes, and retail distribution margins. ${ }^{5}$

Although we will treat ethanol producers, oil refiners, and fuel blenders as if they are unique entities, the corporate structures are actually quite varied and complex. Often, companies that own oil refineries also own fuel blending operations. Moreover, some refining companies are not only blenders, but ethanol producers as well. For particularly large companies, such as Valero, the corporate structure can include refineries, ethanol production facilities, blending facilities, and retail distribution operations. However, while there is a significant amount of vertical integration in the gasoline supply chain, there are many companies that specialize in a particular component. For most products along the supply chain, well-defined spot and futures markets exist, suggesting a large volume of arms-length transactions.

Against this backdrop of private enterprise, and in part underpinning it,

\footnotetext{
${ }^{4} \mathrm{~A}$ small number of retail stations, primarily located in the Midwest, perform splash blending at the pump.

${ }^{5}$ For a more detailed schematic and description of the gasoline production process see (Bullock, 2007).
} 
the US federal government has long supported biofuels - particularly corn ethanol. The justifications for supporting the domestic ethanol industry are varied and have been consistent over time. Perhaps the most prevalent rationale is reducing U.S. dependence on imported oil. Encouraging rural development, enhancing farm incomes, and reducing air pollutant emissions are often invoked as well. Historically, the bulk of support for ethanol was provided in the form of subsidies and import tariffs. Over the past decade tax credits have given way to mandates, particularly the federal Renewable Fuel Standard (RFS).

The VEETC, and a complementary ethanol import tariff, were initially put in place more than three decades ago, though the level of support has varied over time. The Energy Tax Act of 1978 established a 40c per gallon of ethanol tax credit for ethanol blending, regardless of where or how the ethanol was produced. ${ }^{6}$ Shortly thereafter, an import tariff of 40 c per gallon was established to prevent subsidization of imports and thereby protect the domestic industry from Brazilian sugarcane-derived ethanol. Over the years, the levels of the tax credit and the tariff were adjusted. At the time of expiration, the tax credit was at $45 \dot{c}$ per gallon of ethanol and the tariff was at 54c per gallon.

In addition to the VEETC and import tariffs, the ethanol industry has also benefited from mandated blending. With the passage of the Energy Policy Act of 2005, the RFS was born. The RFS targets a minimum percentage of ethanol in finished gasoline for all obligated parties, specifying a lower-bound for the level of ethanol that must be blended. Compliance can be achieved by blending ethanol or purchasing credits (called Renewable Identification Numbers, or RINs) from other obligated parties. At the time of the VEETC expiration, the price of a RIN was effectively zero, suggesting that the mandate was not binding; that is, blending was above the lower-bound established by the RFS (Irwin and Good, 2013). ${ }^{7}$

\footnotetext{
${ }^{6}$ See, for example, Duffield, Xiarchos and Halbrook (2008) and De Gorter and Just (2008).

${ }^{7}$ At the same time that the RFS sets a lower-bound on ethanol blending, an upper-bound exists as well in the form of an E10 "blend wall," which prevents the aggregate proportion of ethanol in the gasoline supply from rising much above ten percent. Infrastructure, legal, and regulatory limitations have limited sales of higher ethanol blends such as E15 and E85
} 
Beyond direct subsidization and import protection, the ethanol industry has also enjoyed increased demand for its product due to local air and water pollution policies. The Clean Air Act Amendments of 1990 required that gasoline be reformulated to reduce smog, which promoted ethanol and MTBE use. By 2006, however, MTBE had been phased out due to concerns over groundwater contamination, leaving ethanol as the oxygenate of choice in the United States.

These policies, together with a significant increase in oil prices over the prior decade, led to substantial growth in the ethanol industry. By 2011, fuel ethanol consumption had reached 12.9 billion gallons, up from 83.1 million gallons in 1981 (Koizumi, 2014). With the advent of the RFS, critics of ethanol policy maintained that the VEETC had become a wasteful policy, providing a subsidy for an activity that had become mandatory. The expansion of ethanol production also caused the total tax expenditure on the subsidy to expand to about $\$ 5$ billion per year. The subsidy was ultimately allowed to expire at the end of 2011.

\section{Previous research on biofuels policy and event studies}

Over the past decade, a substantial literature has emerged that analyzes the welfare and distributional consequences of biofuel policies, primarily through analytic and simulation models. Many of these papers, particularly in recent years, focus on the impacts of a mandate such as the RFS, whereas our interest is on the incidence of the VEETC. De Gorter and Just (2008) analyze the joint impact of an import tariff and ethanol subsidy on prices and output in the ethanol and fuel markets using an analytic model, which they parameterize to simulate the effect of removing the policies. Taheripour and Tyner (2007) investigate the incidence of the ethanol subsidy in an analytic framework, testing their results over a wide-range of parameter values.

Gardner (2007) compares the impact of an ethanol subsidy to a direct corn subsidy on farmers and ethanol producers in a stylized setting, and sim-

and are expected to continue to do so, at least in the short run (Babcock and Pouliot, 2014; Irwin and Good, 2015). 
ulates the short- and long-run outcomes resulting from removal of the ethanol subsidy. Babcock (2008) performs a similar analysis to study the distributional consequences of removing the tax credit, assuming a closed economy. Kruse et al. (2007) and McPhail and Babcock (2008) simulate removal of the tax credit and/or tariff in a stochastic, short-run setting. These studies generally find that the bulk of incidence accrues to ethanol producers, with varying amounts of pass-through to corn farmers. ${ }^{8}$

Abbott (2014) also develops a simple analytic model of corn supply, ethanol production, and gasoline blending and uses short-term data on supply, use, and prices to explain the mechanisms through which biofuels demand influenced corn and other agricultural commodity prices over the 2005-2012 time period. Although the focus of that paper is on investigating how and at which points in time a variety of policy-induced constraints influenced the behavior of agricultural and biofuels markets, the author uses monthly price data to crudely estimate that fuel blenders captured $15 \dot{c}$ of the $45 \dot{c}$ per gallon subsidy, and that the rest was passed along to ethanol producers.

Although our empirical strategy differs substantially from the one implemented in Abbott (2014), the conclusions are similar. However, all of the above studies focus on prospective outcomes of policy changes in a simulation framework, using assumed supply and demand elasticities. In contrast, we use the VEETC phase-out to empirically measure incidence. Most other econometric studies of the corn-ethanol-petroleum complex focus on testing for long-run cointegrating relationships and price volatility transmission; they do not focus on policy impact or incidence. ${ }^{9}$

Methodologically, this research draws from a long literature on event studies, but with an important innovation: we look at calendar spreads in futures markets rather than changes over time in spot prices. For example,

\footnotetext{
${ }^{8}$ An exception is Babcock (2008), which attributes most subsidy incidence to fuel blenders.

${ }^{9}$ For a recent review of empirical work on the relationships between food and fuel prices, see Serra and Zilberman (2013). According to the authors, "the literature concludes that energy prices drive long-run agricultural price levels and that instability in energy markets is transferred to food markets."
} 
Bushnell, Chong and Mansur (2013) use spot prices to determine the stock market valuations of affected firms before and after a sharp devaluation in $\mathrm{CO}_{2}$ permit prices in the EU ETS. ${ }^{10}$ Like other event studies, they then relate this valuation to policy changes, assuming market beliefs effectively capitalize the policy impact into firm valuation.

In this study, we similarly look at price changes to estimate changes in profitability. However, we rely on price differences for futures contracts observed at a single point in time but that differ in terms of specifying delivery before versus after the VEETC expiration. We use this to gauge the markets' beliefs about the incidence of the VEETC. That is, differences in these prices provide evidence as to which prices the market expected to change when the VEETC expired and, in turn, who was benefiting from the subsidy. A major advantage of this approach, relative to using spot prices, is that the information available to the market at the time of measuring the event impact (through future price spreads) is the same. Moreover, examination of other future contracts (beyond the relevant one-month calendar spread) shows how prices are expected to evolve over several months before and after the expiration. In contrast, unobserved information is also changing when one uses spot price changes over time to measure event impacts. Changes in spot prices must be measured over a relatively short interval to reduce this problem. We believe this approach is preferable for event studies more generally whenever heavily traded derivative contracts exist.

\section{Modeling subsidy incidence}

The VEETC is a subsidy provided to fuel blenders for each gallon of ethanol used to produce gasoline. As reviewed by Fullerton and Metcalf (2002) in a general public finance context and noted by Bullock (2007) in the context of ethanol, the economic incidence of a tax or subsidy is often passed along a vertically-linked market chain, manifesting in deviations of equilibrium prices and quantities from the non-distortionary environment. In the case of the

\footnotetext{
${ }^{10}$ For other examples of event study approaches to evaluating impacts of environmental policy on firm profits, see Kahn and Knittel (2006) and Linn (2006, 2010).
} 
supply chain for blended ethanol depicted in Figure 1, this suggests potential deviations in corn, ethanol, RBOB, and retail gasoline prices and quantities. Depending on how these different prices and quantities change, the incidence of the subsidy will differ across corn farmers, ethanol producers, fuel blenders, oil refiners, and consumers.

Following Abbott (2014), we make several assumptions regarding behavior of supply and demand in these markets in order to estimate the subsidy incidence. First, we assume simple linear production technologies for ethanol, $\mathrm{RBOB}$, and gasoline around the time of the subsidy expiration, with

$$
\begin{aligned}
C_{\text {ethanol }} & =0.37 P_{\text {corn }}+C_{0, \text { ethanol }} ; \\
C_{R B O B} & =P_{\text {oil }}+C_{0, R B O B} ; \\
C_{\text {gasoline }} & =0.1\left(P_{\text {ethanol }}-S_{\text {ethanol }}\right)+0.9 P_{R B O B}+C_{0, \text { gasoline }} ;
\end{aligned}
$$

where $C$ represents the unit (per gallon) cost of production for each commodity, $P$ represents market prices for inputs (per gallon or per bushel, for corn), and $C_{0}$ represents other per unit costs. In other words, one gallon of ethanol requires 0.37 bushels of corn (Mosier and Ileleji, 2006), one gallon of blendstock requires one gallon of crude oil, and one gallon of gasoline blends $10 \%$ ethanol and $90 \%$ blendstock. $S_{\text {ethanol }}$ is the ethanol subsidy: either $45 c$ per gallon before or zero after expiration.

Our second assumption is that consumption and production quantity decisions are unrelated to price changes due to subsidy removal in the short run (here, short run is the one to two-month horizon that we examine once the subsidy is removed). Unexpected short-run deviations in supply and demand of ethanol, blendstock, and gasoline are instead met through changes in inventories of each commodity rather than price changes. See Abbott (2014) for evidence and discussion. Persistent price changes will ultimately influence supply and demand decisions as stockpiles change and fixed investments can eventually adjust. ${ }^{11}$

\footnotetext{
${ }^{11}$ Storage capacity is typically one month's supply and stocks are typically at 50 percent of capacity (U.S. Energy Information Adminstration, 2015b,a).
} 
With these assumptions, we can consider what the possible ranges of price changes are for each commodity as a result of removing the subsidy and, ultimately, potential changes in welfare accruing to each stakeholder group. This information is summarized in Table 1 and discussed below.

First, we consider the effect of subsidy removal on ethanol production and further upstream along the agricultural branch in Rows 1 and 2. Subsidy expiration means that each gallon of ethanol blended effectively costs blenders 45 more per gallon due to foregone subsidy receipts. If all of the incidence had been passed up the ethanol/agricultural supply chain, blenders' willingness-to-pay (WTP) for ethanol would reduce by that entire amount, and as a result, the market price of ethanol would decrease by $45 \mathrm{c}$ per gallon. The other extreme possibility is that none of the incidence had been passed up the ethanol/agricultural branch, in which case the change in the price of ethanol per gallon would be zero. Of course, the true incidence could be somewhere in between these two extreme cases, as demonstrated by the interval in Row 1, Column 2.

Some, if not all, of the incidence passed up the agricultural branch could go beyond ethanol producers to corn farmers, captured in Row 2. Once again, if some of the incidence had been passed up the agricultural supply chain, subsidy expiration means that ethanol producers receive a lower price per gallon of ethanol because of the reduced WTP for ethanol by blenders. If the entire agricultural branch incidence accrues to corn farmers, expiration means that ethanol producers WTP for corn would decrease by the full amount of the ethanol price decrease. Because each bushel of corn yields 2.7 gallons of ethanol, the resulting price decrease per bushel of corn would be 2.7 times the change in the price of ethanol per gallon. At the opposite extreme, the agricultural branch incidence could accrue entirely to ethanol producers or further downstream. In this case, the change in the corn price resulting from subsidy removal will be zero. Row 2, Column 2 gives the range of price changes per bushel of corn.

Under the assumptions outlined at the beginning of this section, the price changes in ethanol and corn markets correspond directly to welfare changes for 
corn farmers and ethanol producers. These welfare changes are calculated in Column 3. For corn farmers, the change in welfare due to subsidy expiration is given simply by the change in the price of corn. To calculate the welfare change per gallon of ethanol, the price of corn in bushels needs to be multiplied by a conversion factor of 0.37 bushels per gallon, which is the amount of corn required to produce a gallon of ethanol. For ethanol producers, the change in welfare depends on price changes of both ethanol and corn. Their per-gallon-of-ethanol welfare changes by the ethanol price decrease minus any corresponding decrease in the corn price.

The price and welfare change analysis for oil refiners, reported in Row 3 , is analogous to that of corn farmers. After the subsidy is removed, it costs blenders $45 c$ more per 10 gallons of gasoline produced since there is 1 gallon of ethanol and 9 gallons of RBOB in every 10 gallons of E10. If refiners were able to extract the entire subsidy, blenders' WTP for RBOB decreases by $45 \mathrm{c}$ for 9 gallons of RBOB upon expiry, or 5 c per gallon of RBOB. As a result, the price of RBOB would decrease by a maximum of 5 c per gallon upon expiration of the subsidy. If none of the subsidy had been passed along to refiners, then the RBOB price would not change with removal of the subsidy. If a portion of the subsidy was passed along, then the price change would be somewhere between zero and $-5 \mathrm{c}$ per gallon of RBOB.

Because we assume that the subsidy incidence would not have been passed further upstream to crude oil producers (due to the presence of a global market for oil), any price decrease in RBOB directly reflects the welfare change for oil refiners resulting from loss of the subsidy. The substantial international integration of markets for refined petroleum products also suggests a strong prior that RBOB prices are set internationally, rather than being influenced by ethanol policy. The implication of that assumption would be zero flow-through of the ethanol subsidy to RBOB refiners. While we look to the evidence rather than imposing that assumption, our results are ultimately consistent with it.

The price and welfare change calculations for gasoline consumers and blenders are given in the fifth and sixth rows of Table 1. Subsidy expiration makes each gallon of ethanol effectively $45 c$ more expensive, and ethanol 
makes up 10\% of each gallon of finished gasoline. If the entire subsidy had been passed downstream to consumers, then the price of gasoline would rise by 4.5 c per gallon upon expiration of the subsidy. If none of it had been passed downstream, then there would be no change in the retail gasoline price. In any event, the welfare change per gallon of ethanol faced by consumers would equal ten times the price change per gallon of gasoline.

The welfare change faced by blenders depends on the commodity price changes immediately upstream and downstream of blending. In one extreme, if blenders captured all of the subsidy, there would be no change in any of the commodity price levels. Instead, upon subsidy expiration, blenders' margins would fall by the amount of the subsidy, $45 \mathrm{c}$ per gallon of ethanol blended. For the other extreme, if we found that the per-gallon price changes for ethanol, RBOB, and gasoline (appropriately weighted) add up to 45c, this would imply that all of the subsidy had been fully passed upstream or downstream by the blenders.

Table 1 illustrates three fundamental principles of removing a subsidy in the context of a market supply chain. First, prices tend to decrease upstream of the point where the subsidy enters the market and increase downstream upon subsidy removal. Second, assuming that quantities are fixed in the short run, the overall change in welfare must add up to the full value of the subsidy. Third, Table 1 also demonstrates the difference between economic incidence, which is a calculation of the welfare distribution resulting from a tax or subsidy, and statutory incidence, which is simply an accounting of who physically pays the tax or receives the subsidy. With the conceptual framework established in this section in mind, we proceed by outlining the empirical approach and describing the data.

\section{Empirical Methods, Data, and Results}

The overall empirical strategy is to use calendar spreads in future commodity prices to estimate the price changes in Table 1 . We describe this approach in detail for ethanol and RBOB. For corn and finished wholesale 
gasoline, we are constrained by data limitations and pursue other approaches. We synthesize the results in an overall assessment in Section 6 .

\subsection{Ethanol and RBOB market incidence}

The empirical approach for both ethanol and RBOB relies upon the existence of monthly futures contract markets for each commodity. We exploit the design of these contracts to conduct an analysis similar in concept to event studies that typically use spot prices. Ultimately, the evidence suggests that a significant portion of the subsidy was passed up the agricultural branch of the supply chain: the point estimate is 30c per gallon of ethanol or two-thirds of the subsidy. We find no indication that any part of the subsidy was passed up the petroleum refining branch beyond the blenders themselves.

Each futures contract is identified by a month-year combination when the contract comes due (the "delivery" month). These contracts begin trading on a daily basis years before the delivery month. As an example, we might observe that the December 2011 futures contract opens for trading in November 2009 and continues to trade until November $30^{\text {th }}$, 2011. At this point delivery must be completed by December $3^{\text {rd }}$, 2011. For each commodity, there is a standardized monthly contract with a regular delivery day (e.g., "the $3^{\text {rd" }) ~}$ and a regular closing day for trading of the contract (e.g., "the last day of the preceding month").

Conceptually, we assume the price of the futures contract at a given point in time reflects the expected spot price of the commodity at the time of maturity. ${ }^{12}$ For example, if the contract is set to mature at time $T$, then the future price at time $t$ is given by the equation

$$
F(t, T)=\mathbb{E}_{t}[S(T)]
$$

where $F$ represents a future price, and $S$ represents a spot market price. This is an approximation, as the difference between these two expressions equals a

\footnotetext{
${ }^{12}$ This assumption is supported by, for example, Chinn and Coibion (2014), who find that energy commodity futures prices are generally unbiased and accurate predictors of subsequent prices.
} 
risk premium (Baumeister and Kilian, 2014). Making this approximation, we exploit the combination of this expectation, along with the monthly structure of the futures contract, to examine the subsidy incidence.

Consider a set date for subsidy expiration. In the case of VEETC, the policy was allowed to expire on December $31^{\text {st }}, 2011$. Ethanol blended into motor fuel before this date received the tax credit, and ethanol blended afterwards did not. If we assume as above that the subsidy incidence manifests in commodity prices, then we should see price differences between the December and January futures contracts to the extent that the subsidy was having an effect on ethanol or RBOB prices. The difference in price is due to the fact that the commodity in December is eligible to receive the subsidy whereas the commodity in January is not. Because the future prices for December and January contracts are being observed at the same point in time prior to these dates, the difference in the future prices is not confounded by changes in market conditions that unfold in actual calendar time. ${ }^{13}$ We are also able to look more generally at the pattern of future prices, to see (1) how differences persist into the future beyond January 2012, and (2) at what horizon, prior to the expiration, differences between the December and January contract prices begin to appear. We believe this is a major advantage relative to using spot price changes, which are subject to ongoing incorporation of new market information.

The price difference we use for this identification strategy is known as a one-month calendar spread. For a given point in time $t$, the one-month calendar spread is the difference in the price of two adjacent futures contracts (with prices denoted by $F$ ). If those futures contracts expire on dates $T$ and $T-30$ (about one month difference), then mathematically the calendar spread is given by

$$
C S(t, T)=F(t, T)-F(t, T-30),
$$

\footnotetext{
${ }^{13}$ The future price change could be confounded by changes in expected market conditions other than the expiration of the VEETC, but we are not aware of any other expected policy or market change at that time.
} 
where $C S$ denotes "calendar spread." In the case of the VEETC, the calendar spread of interest is the January 2012 to December 2011 spread (hereafter, Jan12-Dec11). We refer to December's contract as the "leading contract," and January's as the "trailing contract." For RBOB and ethanol, which are produced upstream of the subsidy, we would expect this price spread to be negative as a result of subsidy expiration.

We construct a time series of the Jan12-Dec11 price spread and assess how it evolves over time. We would expect the spread to widen as the market incorporates information that the subsidy is likely to expire. In addition, to distinguish changes in the price spread due to policy expiration from other unobserved factors, we estimate the degree of noise in the series in a simple and flexible way. First, we construct calendar spreads for ethanol and RBOB for several years both prior to and after December 2011. This approach provides a sense for how these spreads typically behave, so that we can assess whether the subsidy expiration induced extraordinary behavior beyond what can reasonably be attributed to typical variation. For the purpose of comparing calendar spreads, we define the object $s=T-t$, which represents the number of days until maturity of the leading contract. For both commodities, we construct separate samples of calendar spreads for each $s$ value. We then order the calendar spreads (excluding Jan12-Dec11) within each group, and calculate the $2.5^{\text {th }}$ and $97.5^{\text {th }}$ percentiles. This gives us a non-parametric version of a 95 percent confidence interval that runs from the first day in which the spread can be calculated up to the day of maturity.

In the case of ethanol, we use the exact procedure just described. For $\mathrm{RBOB}$, the procedure is slightly more complicated. As we demonstrated in Table 1, any price change in RBOB due to VEETC expiration will be at most 5 c per gallon of RBOB. This is a small price change relative to common fluctuations in petroleum markets. In order to gain a more precise estimate, we assume that any incidence accruing to oil refiners did not get passed further upstream in the form of higher crude oil prices. Because crude oil is sold in a global liquids market of which U.S. ethanol is about one percent, it is reasonable to assume that the VEETC would not have any influence on oil 
prices. This allows us to control for changes in oil prices in the RBOB analysis, thereby removing the main source of RBOB price volatility.

We control for oil price variation by estimating the following model:

$$
\begin{aligned}
C S_{R B O B}(t, T)= & \beta_{0}+\alpha_{1} C S_{\text {oil }}(t, T-11)+\alpha_{2} C S_{\text {oil }}(t-1, T-11) \\
& +\alpha_{3} C S_{\text {oil }}(t-2, T-11)+\beta_{1} C S_{\text {oil }}(t, T+11) \\
& +\beta_{2} C S_{\text {oil }}(t-1, T+11)+\beta_{3} C S_{\text {oil }}(t-2, T+11)+\epsilon(t, T),
\end{aligned}
$$

where $C S_{x}(t, T)$ represents a calendar spread for commodity $x$ on date $t$ for which the trailing contract matures on date $T$. Because oil futures contracts mature in the middle of the month prior to the contract month, i.e., around eleven trading days, it is not obvious whether to include the leading oil spread or the trailing spread, where the term "leading" is again meant to express a calendar spread that matures first. Therefore, we include both leading and lagging calendar spreads for Brent crude oil prices as regressors. ${ }^{14}$ We also include one- and two-day lags for both types of calendar spreads. We estimate the model separately for each calendar spread in the sample period (i.e., the average daily value of the Jan12-Dec11 calendar spread observed over the entire period where that calendar spread is traded), and calculate the regression residuals. This gives us a set of residual RBOB price spreads, controlling for oil prices, that are analogous to the ethanol price spreads discussed above. We then use these spreads to create a quantile interval in order to gauge whether the RBOB spread behaves atypically near the point of subsidy expiration.

Given the approaches described above, the only data we require are futures contract price data for ethanol, $\mathrm{RBOB}$, and crude oil. We use daily price

\footnotetext{
${ }^{14}$ When including the leading calendar spread as a regressor, we encounter an additional difficulty with timing. The leading contract of the leading spread matures about half a month prior to the leading contract of the RBOB spread. Therefore, if we use the pure calendar spread model, the best we can do is measure the RBOB price change around eleven trading days prior to maturity. Alternatively, we can replace the price of the leading contract of the leading spread with the oil spot price for the last half month. We implement both procedures, finding that there is little difference in the results.
} 
data on futures contracts from January 2007 through July 2013. ${ }^{15}$ The ethanol futures contracts are traded on the Chicago Mercantile Exchange (CME), while the RBOB and Brent crude oil futures contracts are traded on the New York Mercantile Exchange (NYMEX). All futures price series were accessed via Bloomberg. As noted above, the delivery dates for the futures contracts vary across commodities. For ethanol, the contracts mature on the third trading day of the contract month. Brent contracts mature on the last business day prior to the $15^{\text {th }}$ day of the month prior to the contract month, i.e., the December Brent contract matures in mid-November. RBOB contracts mature on the last day of the month prior to the contract month.

The raw data on ethanol futures contract prices around the VEETC expiration is shown graphically in Figure 2. The figure plots the spot price of ethanol (dashed line) as well as the futures strip for August 2011 through April 2012 as of several different dates during that time period. Each future strip shows the price for all future month contracts as of a given point in calendar time, connected by a line. We see that, prior to January 2012, the ethanol futures market became increasingly backwardated - meaning that contracts for more distant delivery dates traded at lower prices - as the date of subsidy expiration approached. This backwardation was especially pronounced around the Dec11-Jan12 contract months. In contrast, from January 2012 forward, the ethanol market traded in contango, meaning that contracts in the more distant future traded at higher prices.

The black dots in the figure represent the prices of the December 2011 and January 2012 contracts at the time that the December 2011 contract expired (December $5^{\text {th }}, 2011$ ). In noting the vertical distance between the two points, we can see how stark the price difference was between those contracts relative to similar price spreads both before and particularly after that time (e.g., one-month calendar spreads as the leading contract expires). Moreover, comparing the Jan12-Dec11 spread at earlier dates suggests that the sub-

\footnotetext{
${ }^{15}$ We chose to begin our exploration with 2007 data rather than 2006 (the earliest year for which a market existed for ethanol futures) to avoid noise occurring as a result of MTBE phaseout and participants acclimating to a new market.
} 
sidy expiration might have begun being reflected in the market as early as the beginning of September 2011 and increased as the year progressed. The Jan12-Dec11 spread viewed in August 2011 was almost imperceptible.

The notion of a gradually increasing certainty over subsidy expiration is reasonable, especially because of the long-term persistence of the subsidy as well as the last minute extension that had been granted to the VEETC just one year earlier. ${ }^{16}$ It could also be the case that the futures market had expected the December 2011 expiration at an earlier time, but gained information over time about the incidence of the subsidy captured by ethanol producers.

While Figure 2 suggests a reaction in ethanol futures markets to the VEETC expiration that is larger than the six other one-month calendar spreads just prior to maturity of the leading contract, it is hard to turn that into a probabilistic statement. To get a better sense of how significant the size of the Jan12-Dec11 spread was statistically, we calculate the $2.5^{\text {th }}$, median, and $97.5^{\text {th }}$ quantile of calendar spreads over the 2007-2013 sample, excluding Jan12-Dec11. We group the calendar spreads based on time until the leading contract matures, as described above. The results are plotted in Figure 3, along with the Jan12-Dec11 spread. The vertical axis represents price spreads, in dollars per gallon of ethanol, while the top horizontal axis represents the number of days until maturity of the leading month contract (since they all mature at different dates) of the price spreads used to construct the quantile interval. The bottom horizontal axis tracks the observed Jan12-Dec11 spread over calendar time.

Excluding the Dec11-Jan12 spread, the ethanol price series appears to exhibit a very slight degree of backwardation, perhaps a penny per month for the median spread, when the leading contract is close to expiration. The median (or $50^{\text {th }}$ percentile), represented by the solid black line in the figure, hovers at $0 \dot{c}$ until around 90 days until maturity, at which point it decreases very slightly and remains slightly negative. The red lines capture the empirical

\footnotetext{
${ }^{16}$ For this reason, one could also posit that the effect of the subsidy expiration wasn't fully reflected in the ethanol futures market by December contract maturity. If this is the case, then we are underestimating the benefit of the policy to ethanol producers.
} 
$95^{\text {th }}$ percentile of spreads, and demonstrate that the distribution of spreads is skewed downward (negatively), a feature that appears stronger as the leading contracts approach maturity. The Jan12-Dec11 spread, represented by the blue line, declines steeply as the December delivery date draws near, finishing at about -30c per gallon of ethanol, which is well beyond the lower bound of the $95 \%$ quantile interval. This suggests that ethanol producers were receiving about two-thirds of the $45 c$ subsidy prior to its expiration, some of which could have in turn been passed upstream to corn farmers.

We can use the $95^{\text {th }}$ quantile interval to construct a confidence interval for the effect of subsidy expiration on calendar spread, assuming the variation observed in the other calendar spreads is independent of any subsidy expiration effect, and therefore might be adding a certain amount of asymmetric noise to this measurement. On the day of expiration, the $95^{\text {th }}$ quantile interval ranges from $-15 \dot{c}$ to $5 \dot{c}$ per gallon, essentially around $0 \dot{c}$. Based on the point estimate of -30c per gallon as the "subsidy expiration" effect based on the Dec11-Jan12 calendar spread, it would be unusual $(<2.5 \%$ probability) for a true subsidy expiration effect of anything less negative than -15 c to have randomly produced an observation of -30 c. Similarly, it would be unusual $(<2.5 \%$ probability $)$ for a true subsidy effect of anything more negative than -35 c to have generated a -30 c point estimate. This yields a $95 \%$ confidence interval, $[-35 \dot{c},-15 \dot{c}]$.

To investigate whether any incidence was passed up the petroleum branch, we present an analogous illustration for the RBOB market in Figure 4. However, unlike ethanol, we do not construct the plots directly from the RBOB spreads. Instead, we first estimate equation (4) to control for oil price changes, and then perform the same analysis as we did for ethanol, but on the RBOB regression residuals. To allow easier comparison of incidence across the various commodities, we also convert the residuals into equivalent cents per gallon of ethanol blended by multiplying the RBOB prices by nine, since there are nine gallons of RBOB for every gallon of ethanol blended.

As a result, the vertical axis in Figure 4 represents RBOB price spreads (for nine gallons of RBOB or equivalent to one gallon of blended ethanol) after 
removing the variation in price spreads due to oil price changes. The black line for the median price spread is around zero for all days to maturity. The Jan12-Dec11 spread maintains a price near zero until mid-September 2011, drops in early October, and climbs back up above zero during the month of November. By the last trading day for the December contract, the spread is slightly negative, finishing at about $-7 \mathrm{c}$, or slightly below the median spread of about $-6 c$ on the day of maturity over the entire sample period. Additionally, the quantile interval depicted by the red lines shows some downward skewness, particularly as maturity of the lead contract approaches. ${ }^{17}$ We note that for almost all measurements in the last 30 days of the contracts, the lower bound of the interval exceeds the maximum incidence of $45 \mathrm{c}$ per nine gallons of RBOB that could accrue to oil refiners: this negates our ability to find precise statistical evidence that the VEETC expiration resulted no price change for RBOB. That is, while we cannot reject the null hypothesis that there was no effect on RBOB prices as a result of the VEETC expiration, an estimated 95\% quantile interval includes both zero and 100\% incidence. Nonetheless, the point estimate suggests very little if any impact, consistent with our prior based on internationally integrated refined petroleum markets.

\subsection{Corn market incidence}

Given the evidence suggests that a significant portion of the subsidy was passed upstream to ethanol producers, we next investigate whether some of it was passed further upstream to corn farmers. This would be consistent with a Ricardian view that land, as an inelastic resource, capitalizes much of the value of agricultural products (e.g., Mendelsohn, Nordhaus and Shaw (1994)), and recent empirical evidence that farms and farmers capture nearly 100 percent of farm subsidies (Kirwan, 2009). We find some suggestive evidence that this occurred. However, because of data limitations due to the nature of corn futures markets, the evidence is more suggestive than conclusive.

As with ethanol, standardized futures contracts exist for corn and are

\footnotetext{
${ }^{17}$ For the day of maturity, this skewness is illustrated by the lower bound on the interval, which is almost three times further away from zero than the upper bound.
} 
traded through the CME, which we collected via Bloomberg for January 2007 through July 2013. These contracts mature on the business day immediately preceding the $15^{\text {th }}$ day of the contract month. Unlike ethanol and RBOB, however, there are not corn futures contracts for every calendar month. Instead, corn futures contracts exist only for March, May, July, September, and December. This fact, coupled with the highly seasonal nature of agricultural commodity markets, forces us to alter the approach to calculating price changes in the corn market.

The alternative approach is demonstrated in Figure 5. In lieu of a Jan12Dec11 spread, which cannot be constructed for the corn market, we base the analysis on the Mar12-Dec11 spread. The rationale for using this spread is the same as before, but this procedure could be more prone to picking up nonVEETC effects than the single month spread. In Figure 5, we plot the spreads for all March-December spreads from March 2008 to March 2013. We focus only on the March-December spreads due to the existence of highly seasonal effects in corn futures spreads. For example, the typical March-December spread exhibits much different behavior than the typical September-July spread. Because of this more limited set of observations, we look at all of the available series of spreads, rather than summarizing in a quantile interval.

The vertical axis in the figure once again represents the spread in contract prices between adjacent contracts. For the sake of comparison, the prices have been converted to per gallon of ethanol equivalent, assuming the 0.37 bushels per gallon conversion discussed in the context of Equation (1). For the four earliest contracts, plotted as solid black lines, the spreads exhibit varying degrees of contango (i.e., all spreads are positive), which is typical behavior in grains markets. Because crops are costly to store, a premium, often called the carry, is provided as compensation. ${ }^{18}$ When the leading contract is between 150 and 180 days to maturity, the spread tends to be about 4 c per gallon. The final spread at maturity over this time horizon increases slightly to about $5 \mathrm{c}$ per gallon (i.e., the average of the Mar08-Dec07, Mar09-Dec08, Mar10-Dec09, and Mar11-Dec10 contracts).

\footnotetext{
${ }^{18}$ For example, see Yoon and Brorsen (2002).
} 
The spread of interest, Mar12-Dec11, is represented by the dashed blue line. It exhibits similar behavior until around 30 days before maturity, at which point it decreases sharply and eventually finishes around 0ç per gallon, or about 5 per gallon lower than is typical. The Mar13-Dec12 spread, represented by the solid green line, exhibits atypical behavior as well, trading in an atypically low degree of contango or even backwardation for most of the last 120 days until maturity of the December 2012 contract. The atypical behavior

of the Mar13-Dec12 spread can be explained by drought conditions in 2012 that resulted in a short supply of new corn to be sold in December of that year, causing prices for the leading contract to increase. Right before that maturity date, however, the Mar13-Dec12 spread converges rapidly toward a more typical carry premium. Together, the March-December spreads in this period (excluding Mar12-Dec11) have a mean of $5 c$ and a standard deviation of 1c. Since the Mar12-Dec11 spread finished at about 0c per gallon, this suggests a point estimate of $-5 \mathrm{c}$ per gallon change in the corn price due to the subsidy expiration, with a two-standard deviation confidence interval of $[-3 \dot{c},-7 \dot{c}]$.

The takeaway from this analysis is that there is some suggestive evidence that a portion of the subsidy incidence was being passed upstream from ethanol producers to corn farmers, based on the corn spread for Mar12-Dec11 at maturity being about 5 c per gallon lower than normal, but it is difficult to make any strong statements because of the small number of comparable contracts.

\subsection{Finished gasoline market incidence}

Unlike in the cases of ethanol, RBOB, and corn, there are no standardized futures contracts for finished gasoline. As a result, the preferred approach is not feasible. As an alternative, we turn to finished gasoline spot market prices and blender margins to provide insights. Ultimately, we find no evidence that any incidence was passed downstream through wholesale finished gasoline prices to consumers. Instead it appears that any subsidy not passed upstream through the ethanol supply chain was captured by blenders. 
Having explored all of the upstream incidence, identifying the downstream effect on finished gasoline prices will simultaneously identify the net effect on the blender margin or vice-versa. Given the estimates of ethanol and RBOB price changes, we can see from Table 1 that the blender's welfare effect now depends only on the price change of finished gasoline. We focus on estimating the change in the blender margin because the evidence suggests the blender margin is a stationary time series, while gasoline spot prices are not.

We define the blender margin per gallon of ethanol blended to be equal to 10 times the finished gasoline price, minus the prices per gallon of ethanol and RBOB (weighted by their volumetric contributions to 10 gallons of finished product), plus any subsidy paid to the blender:

$$
B M(t)=10 P_{\text {gasoline }}(t)-9 P_{R B O B}(t)-P_{\text {ethanol }}(t)+s_{\text {ethanol }}(t) .
$$

Here, $s_{\text {ethanol }}(t)$ equals $45 \mathrm{c}$ prior to a cut-off date (chosen as December $5^{\text {th }}$, 2011) for collecting the VEETC, and zero afterwards. ${ }^{19}$ Comparing this to the blender welfare expression in Table 1, we can see that any change to the blender margin in a window around the expiration of the VEETC subsidy (along with consequent changes in gasoline, RBOB, and ethanol prices) exactly equals the welfare effect per gallon of ethanol.

We compute the blender margin using daily wholesale spot price data on the three commodities from 2011 and 2012. The ethanol and RBOB data are both New York Harbor spot prices acquired from Bloomberg, while the gasoline data are reformulated E10 rack prices in New York City acquired from Oil Price Information Service (OPIS). We chose prices in the same market in order to estimate any effect as precisely as possible, and we chose to work with wholesale prices for the same reason. ${ }^{20}$

\footnotetext{
${ }^{19}$ Blenders must have purchased ethanol in advance of December $31^{\text {st }}, 2011$, in order to blend it with gasoline on or before that date and collect the subsidy. Therefore, the cut-off for defining $s_{\text {ethanol }}(t)$ equal to $45 \mathrm{c}$ will be a date prior to December $31^{\text {st }}, 2011$. We choose a cutoff of December $5^{\text {th }}, 2011$, which corresponds to the date of the "pre-expiration" price used in our calendar spread analysis of ethanol prices. It is unclear whether ethanol sold at later dates in December would be blended in time to qualify for the subsidy.

${ }^{20}$ Retail and wholesale gasoline prices follow one another very closely with about a $70 c$ average retail margin, which reflects transportation costs, taxes, and mark-ups (Irwin and
} 
The price series over the sample period are plotted in Figure 6. Ethanol, RBOB, and gasoline prices are identified as the green, orange, and blue lines, respectively. The date of subsidy expiration on December $31^{\text {st }}, 2011$ is marked by the vertical gray line. Right before this cutoff, ethanol spot prices decline sharply, consistent with the earlier results. As noted earlier, the price of finished gasoline (as well as ethanol and RBOB) evolves according to a random walk. ${ }^{21}$ Unsurprisingly, finished gasoline and RBOB prices move very closely together. Meanwhile, a cointegrating regression using the three price series, suggests the existence of one cointegrating vector (based on a formal Johansen test for cointegration) with the following coefficients on the prices: $10 P_{\text {gasoline }}-8.9 P_{R B O B}-1.1 P_{\text {ethanol }}{ }^{22}$ Because the estimated cointegrating vector generates coefficients on $P_{\text {ethanol }}$ and $P_{R B O B}$ that are close to and statistically indistinguishable from the theoretical relationship in Equation (5), we simply impose (5) to define the blender margin.

The constructed blender's margin is plotted in Figure 7 . In line with the aforementioned statistical tests, the figure suggests that the blender's margin series is stationary, and a unit root null is soundly rejected. It also demonstrates that the blender's margin fluctuated substantially during 2011 and 2012 , ranging from zero to $\$ 3$ per gallon of ethanol, with a standard deviation of almost 60 c. It also does not suggest any obvious visible change in the level of the pre- and post-expiration blender's margin.

We use standard autoregressive modeling techniques to form a precise estimate of the change at the time of the VEETC expiration. Specifically, we estimate the following model:

$$
B M_{t}=\varphi_{0}+\varphi_{s} \mathbb{1}\left\{t>T^{*}\right\}+\sum_{i=1}^{P} \varphi_{i} B M_{t-i}+\epsilon_{t}
$$

Good, 2011).

${ }^{21}$ For each commodity, Phillips-Perron tests fail to reject the null hypothesis of a unit root.

${ }^{22}$ In order to precisely estimate the cointegrating relationship, we use price data from 2007 through 2012. The confidence intervals for the coefficients on $P_{\text {ethanol }}$ and $P_{R B O B}$ contain 1 and 9 , respectively, at any reasonable level of significance. 
where $\epsilon_{t}$ is white noise and $T^{*}=$ December $5^{\text {th }}, 2011$, consistent with the assumed definition of $s_{\text {ethanol }}(t)$ above. We are interested in the change in the unconditional mean of the blenders margin resulting from subsidy expiration. Under this model specification, this is estimated by the following transformation of the parameters:

$$
\Delta B M=\frac{\hat{\varphi}_{s}}{1-\sum_{i=1}^{P} \hat{\varphi}_{i}},
$$

where $\triangle B M$ is the estimated change in the blender's margin resulting from expiration. Under this construction of the blender's margin variable defined by (5), we will expect to see a change in the blender's margin of between -45 c (if the blender was capturing the entire subsidy) and $0 c$ (if the entire subsidy was being passed along). To maintain consistency with the earlier analysis focused on the months just before and just after the subsidy expired, we restrict the sample to the six months before and after the expiration breakpoint, $T$. Other sample window choices yield similar results. A Box-Jenkins approach to model specification suggests an $A R$-model with $P=3$. Consistent with our visual interpretation, the estimation fails to identify any significant decrease in the blender's margin constant, which is calculated according to Equation (7). We find a point estimate of $14 \dot{c}$ with a $95 \%$ confidence interval of [36c, 8c $]$. The point estimate suggests that around two-thirds of the subsidy was passed along through price changes, which coincides with the previous estimate of the incidence accruing to the agricultural branch. Taking the previous results at face value, the point estimate suggests that none of the subsidy incidence was passed downstream to gasoline consumers. While the confidence interval on this estimate of the blender margin is quite large, taken together with the other estimates of price changes, it reinforces the view that the majority of the VEETC was being captured by ethanol and/or corn producers, some was captured by blenders, and little if any was being captured by consumers or petroleum refiners. 


\subsection{Summary}

The previous sections produced estimates of price changes in ethanol of $-30 \dot{c}$ (CI: $[-15 \dot{c},-35 \dot{c}])$, price changes in RBOB of 0c (CI: [-50c, 140غे]), price changes in corn of $-5 \dot{c}(\mathrm{CI}:[-3 \dot{c},-7 \dot{c}])$, and changes in the ethanol blender margin of $-14 \grave{c}(\mathrm{CI}:[-36 \dot{c}, 8 \dot{c}]$ ) (all expressed per gallon of blended ethanol). We translate these estimates into incidence by stakeholder groups in Table 2.

For ethanol producers, we find an incidence point estimate of $25 \mathrm{c}$ per gallon of ethanol (Row 1). This is calculated by subtracting the estimated $5 \mathrm{c}$ per gallon of ethanol price decrease for corn from the estimated 30c per gallon decrease in ethanol prices. ${ }^{23}$ For corn farmers, the incidence point estimate (5c per gallon of ethanol) and bounds (3c to $7 \dot{c}$ ) are equivalent to the price decrease in the corn price (Row 2).

The incidence point estimate and range for oil refiners, fuel blenders, and gasoline consumers are displayed in Rows 3, 4, and 5. Here, we round the estimated $14 c$ change in the blender's margin as a result of subsidy expiration to $15 \mathrm{c}$. Along with the 30c point estimate for ethanol producer and corn farmers, this leaves a residual point estimate of zero for gasoline consumers and oil refiners (consistent with our prior knowledge about internationally integrated refined petroleum markets). ${ }^{24}$ To construct confidence intervals for these point estimates, we rely on the confidence estimate of the effect on ethanol prices because the direct estimates of blender margins and RBOB price changes were uninformative. Namely, if values less than 15 c are not included in the estimated effect on ethanol prices, the confidence interval for incidence

\footnotetext{
${ }^{23}$ To construct an approximate confidence interval, we shift the ethanol price confidence interval by $5 c$ and extend it by $2 \phi$ (to account for the error in the corn price estimate). This will be conservative, as the true confidence interval should be slightly smaller.

${ }^{24} \mathrm{It}$ is plausible that $1 \mathrm{c}$ went to oil refiners based on the RBOB point estimate. Or, assuming the oil refiners received no benefit from the subsidy, one could argue that $1 \mathrm{c}$ flowed to consumers based on combining the estimated $14 \dot{c}$ for blenders and $30 \dot{c}$ for ethanol producers/corn farmers, and subtracting from $45 \dot{c}$. However, $1 \dot{c}$ is of such insignificant magnitude and so well within the noise of the gasoline and RBOB markets that, for simplicity, we round the fuel blender incidence to $15 \mathrm{c}$ and the oil refiner/gasoline consumer incidence to zero.
} 
on oil refiners, consumers, and blenders, cannot include values above 30ç. We further assume subsidies have only positive welfare effects on recipients, yielding a lower bound of zero.

\section{Conclusion}

At the time of its expiration, there was considerable debate about who was benefiting from the VEETC. This paper examines this question through a detailed, empirical analysis of price changes at the time the subsidy expired, in an event-study framework. Where possible, we used calendar spreads of futures prices, giving us a relatively clean indication of how the market expected prices to change for upstream commodities. Since futures price data was not available for measuring downstream incidence on gasoline prices, we instead directly estimated the blender's margin using spot price data, and assessed consumer impacts as the residual.

We found compelling evidence that an estimated two-thirds of the subsidy was passed up the agriculture chain to ethanol producers, with a lower bound of one-third. Moreover, we found suggestive evidence that a small portion of the subsidy (around $5 c$ per gallon of ethanol blended) was further passed upstream to corn farmers, though the data is more limited. Our direct estimate of the blender's take is 15 c per gallon, with a confidence interval that includes zero. This yields a point estimate for the consumer incidence of essentially zero, as well as being consistent with the (noisy) estimate of little, if any, incidence on refineries. This matches our prior that gasoline blendstock

prices are independent of ethanol policy, being determined in internationally integrated product markets.

These results are consistent with previous work based on analytic and simulation modeling that generally argued ethanol producers benefited the most from VEETC, with some pass-through to corn farmers (De Gorter and Just, 2008; Taheripour and Tyner, 2007; Gardner, 2007; Kruse et al., 2007; McPhail and Babcock, 2008). It also provides partial support for Babcock (2008), who attributes most subsidy incidence to blenders. Our results match 
up closely to Abbott (2014), who found a similar 2:1 incidence split between ethanol producers and blenders. Unlike these prior studies, however, we have empirically estimated the incidence based on the VEETC elimination rather than simulating the policy with assumed elasticities. The approach introduces a new methodology for assessing the impact of policy and other market changes through futures contracts. The findings are relevant both for understanding the financial incidence of one of the largest energy subsidies in US history, as well as the market structure underpinning an industry that continues to be subject to substantial policy intervention.

\section{References}

Abbott, Philip. 2014. "Biofuels, Binding Constraints and Agricultural Commodity Price Volatility." In The Economics of Food Price Volatility. , ed. J.P. Chavas, D. Hummels and B.D. Wright. University of Chicago Press.

Anderson, Soren T. 2012. "The Demand for Ethanol as a Gasoline Substitute." Journal of Environmental Economics and Management, 63: 151-168.

Babcock, Bruce A. 2008. "Distributional Implications of U.S. Ethanol Policy." Review of Agricultural Economics, 30(3): 533-542.

Babcock, Bruce A., and Sebastien Pouliot. 2014. "Feasibility and Cost of Increasing US Ethanol Beyond E10." CARD Policy Briefs (14-PB 17). Center for Agricultural and Rural Development, Iowa State University.

Baumeister, Christiane, and Lutz Kilian. 2014. "A General Approach to Recovering Market Expectations from Future Prices With an Application to Crude Oil." Working Paper. http://wwwpersonal.umich.edu/likilian/bk4_091314withappendix.pdf.

Brester, Gary W. 2012. "Corn." Agricultural Marketing Resource Center, http://www.agmrc.org/commodities_products/grains_oilseeds/corn_grain/. 
Bullock, David S. 2007. "Ethanol Policy and Ethanol Politics." In CornBased Ethanol in Illinois and the U.S.. Chapter 9. University of Illinois Department of Agricultural and Consumer Economics.

Burtraw, Dallas, and Karen Palmer. 2008. "Compensation Rules for Climate Policy in the Electricity Sector." Journal of Policy Analysis and Management, 27(4): 819-847.

Bushnell, James B., Howard Chong, and Erin T. Mansur. 2013. "Profiting from Regulation: Evidence from the European Carbon Market." American Economic Journal: Economic Policy, 5(4): 78-106.

Chinn, Menzie D., and Olivier Coibion. 2014. "The Predictive Content of Commodity Futures." Journal of Futures Markets, 34(7): 607-636.

De Gorter, Harry, and David R. Just. 2008. "The Economics of the U.S. Ethanol Import Tariff with a Blend Mandate and Tax Credit." Journal of Agricultural \&3 Food Industrial Organization, 6(2).

Duffield, James A., Irene M. Xiarchos, and Steve A. Halbrook. 2008. "Ethanol Policy: Past, Present, and Future." SDL Review, 53: 425-453.

Fullerton, Don, and Gilbert E. Metcalf. 2002. "Tax Incidence." Handbook of Public Economics, 4: 1787-1872.

Gardner, Bruce. 2007. "Fuel Ethanol Subsidies and Farm Price Support." Journal of Agricultural $\& 3$ Food Industrial Organization, 5(4).

Greene, Nathanael, and Sasha Lyutse. 2010. "Let the VEETC Expire: Moving Beyond Corn Ethanol Means Less Waste, Less Pollution, and More Jobs." National Resources Defense Council Fact Sheet.

Illinois Corn. 2011. "Ethanol Subsidy Expires Leaving Uncertainty at the Pump." http://www.ilcorn.org/media/dailyupdate/article/2011/12/ethanol-subsidy-expires-leaving-uncertainty-atthe-pump. 
Irwin, Scott, and Darrel Good. 2011. "Trends in Crude Oil and Gasoline Prices." farmdoc daily, Department of Agricultural and Consumer Economics, University of Illinois at Urbana-Champaign, October 6, 2011.

Irwin, Scott, and Darrel Good. 2013. "Exploding Ethanol RINs Prices: What's the Story?" farmdoc daily, Department of Agricultural and Consumer Economics, University of Illinois at Urbana-Champaign, March 8, 2013.

Irwin, Scott, and Darrel Good. 2015. "What if the EPA Implements RFS Mandates for Renewable Fuels at Statutory Levels?" farmdoc daily, Department of Agricultural and Consumer Economics, University of Illinois at Urbana-Champaign, February 19, 2015.

Kahn, Shulamit, and Christopher R. Knittel. 2006. "The Impact of the Clean Air Act Amendments of 1990 on Electric Utilities and Coal Mines: Evidence from the Stock Market." University of California Energy Institute Working Paper CSEM WP 118.

Kirwan, Barrett E. 2009. "The Incidence of U.S. Agricultural Subsidies on Farmland Rental Rates." Journal of Political Economy, 117(1): 138-164.

Koizumi, Tatsuji. 2014. Biofuels and Food Security: Biofuel Impact on Food Security in Brazil, Asia, and Major Producing Countries. Springer.

Kruse, John, Patrick Westhoff, Seth Meyer, and Wyatt Thompson. 2007. "Economic Impacts of Not Extending Biofuel Subsidies." AgBioForum, 10(2): 94-103.

Linn, Joshua. 2006. "Stock Prices and the Cost of Environmental Regulation." Center for Energy and Environmental Policy Research (CEEPR) 06-011.

Linn, Joshua. 2010. "The Effect of Cap-and-Trade Programs on Firms' Profits: Evidence from the Nitrogen Oxides Budget Trading Program." Journal of Environmental Economics and Management, 59(1): 1-14. 
McPhail, Lihong Lu, and Bruce A. Babcock. 2008. Short-Run Price and Welfare Impacts of Federal Ethanol Policies. Center for Agricultural and Rural Development.

Mendelsohn, Robert, William D. Nordhaus, and Daigee Shaw. 1994. "The Impact of Global Warming on Agriculture: A Ricardian Analysis." American Economic Review, 84(4): 753-771.

Mosier, Nathan S., and Klein Ileleji. 2006. "How Fuel Ethanol Is Made From Corn." Purdue Extension ID-328, https://www.extension.purdue.edu/extmedia/id/id-328.pdf.

National Research Council. 2010. Hidden Costs of Energy: Unpriced Consequences of Energy Production and Use. National Academies Press.

Serra, Teresa, and David Zilberman. 2013. "Biofuel-Related Price Transmission Literature: A Review." Energy Economics, 37: 141-151.

Taheripour, Farzad, and Wallace Tyner. 2007. "Ethanol Subsidies, Who Gets the Benefits?"

U.S. Energy Information Administration. 2011. "Direct Federal Financial Interventions and Subsidies in Energy in Fiscal Year 2010." http://www.eia.gov/analysis/requests/subsidy/archive/2010/pdf/subsidy.pdf.

U.S. Energy Information Adminstration. 2014. "Frequently Asked Questions." http://www.eia.gov/tools/faqs/faq.cfm?id=327\&t=9.

U.S. Energy Information Adminstration. 2015a. "Petroleum and Other Liquids - Data." http://www.eia.gov/petroleum/storagecapacity/.

U.S. Energy Information Adminstration. 2015b. "Petroleum and Other Liquids - Working and Net Available Shell Storage Capacity." http://www.eia.gov/petroleum/storagecapacity/.

Wolfram, Gary. 2011. "The Energy Emperor's Ethanol Wardrobe Looks Mighty Bare." http://www.washingtonexaminer.com/the-energy-emperorsethanol-wardrobe-looks-mighty-bare/article/39273. 
Yoon, Byung-Sam, and B. Wade Brorsen. 2002. "Market Inversion in Commodity Futures Prices." Journal of Agricultural and Applied Economics, 34(3): 459-476. 


\section{Tables and Figures}

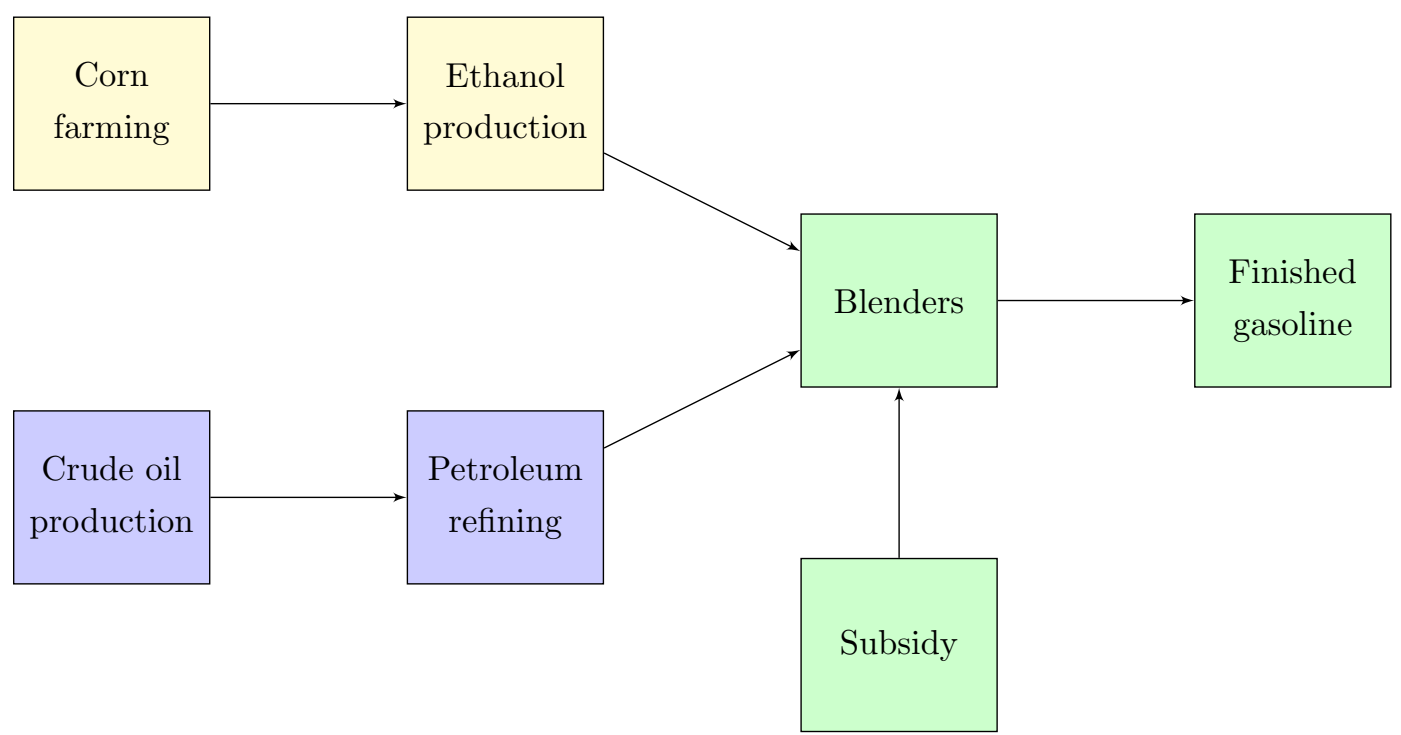

Figure 1: U.S. gasoline production with ethanol blending 


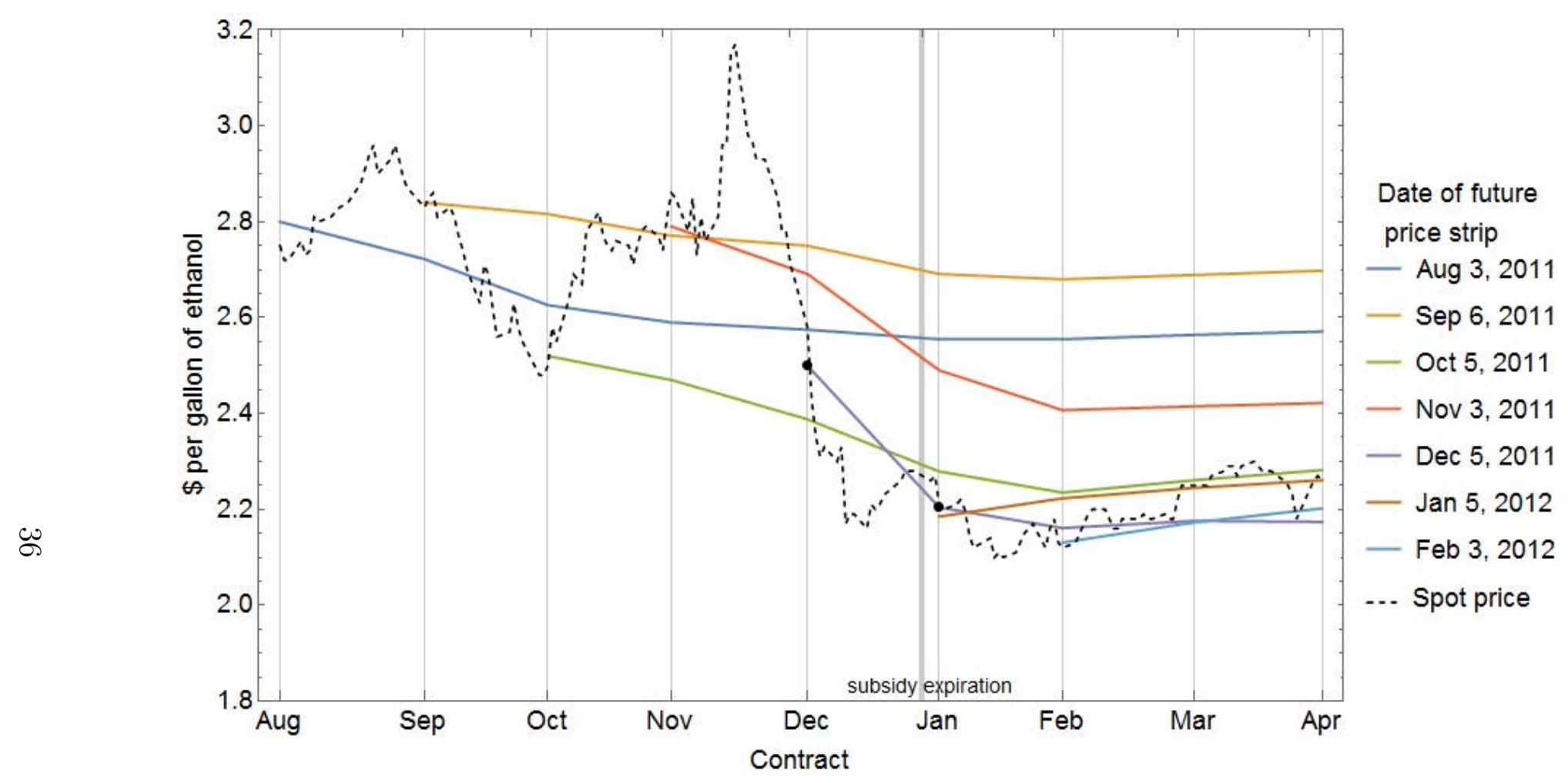

Figure 2: Ethanol futures strip around subsidy expiration, August 2011 - April 2012 contracts 


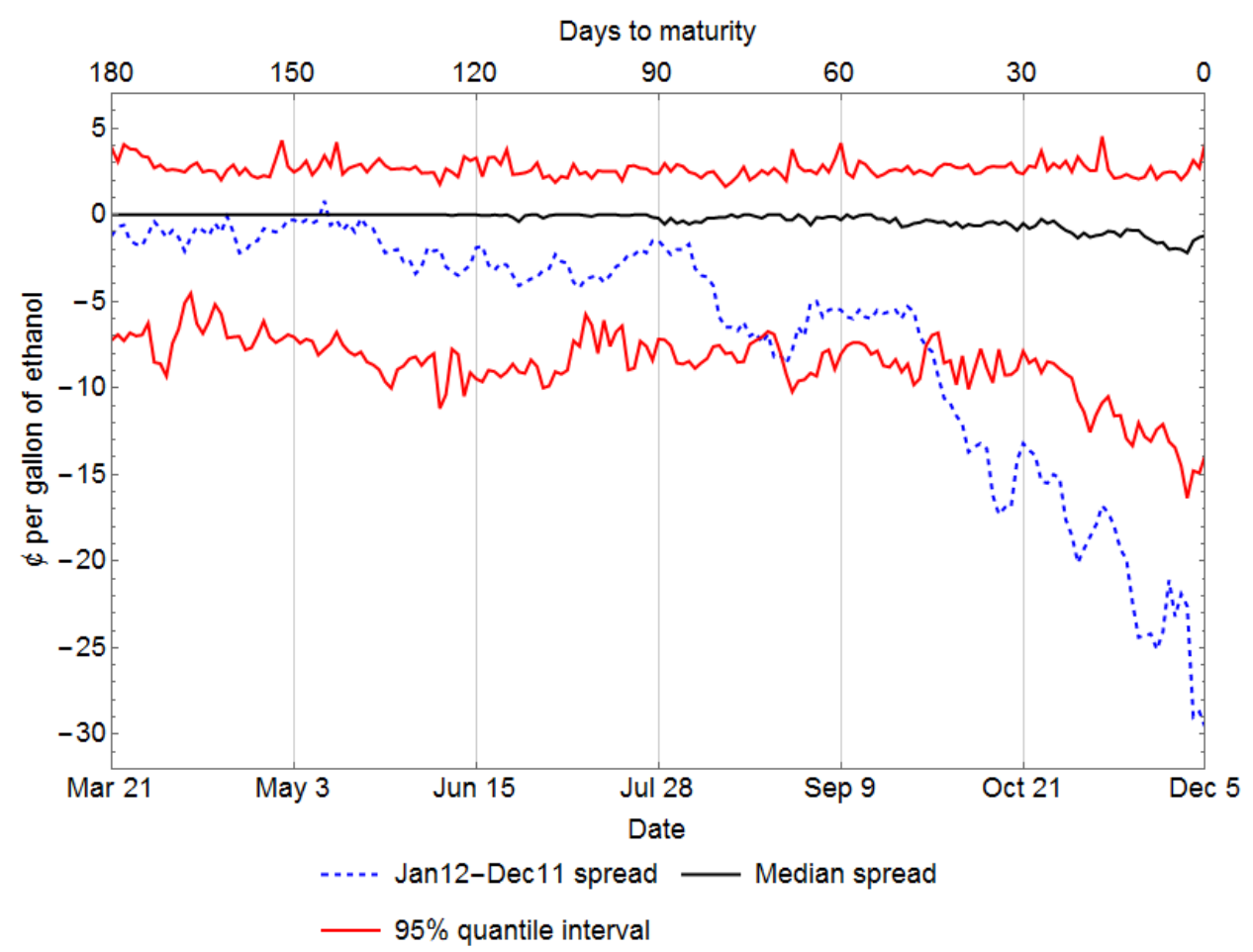

Figure 3: Ethanol price spread for January 2012 - December 2011 versus other one month calendar spreads, conditional on the same number of days to maturity 


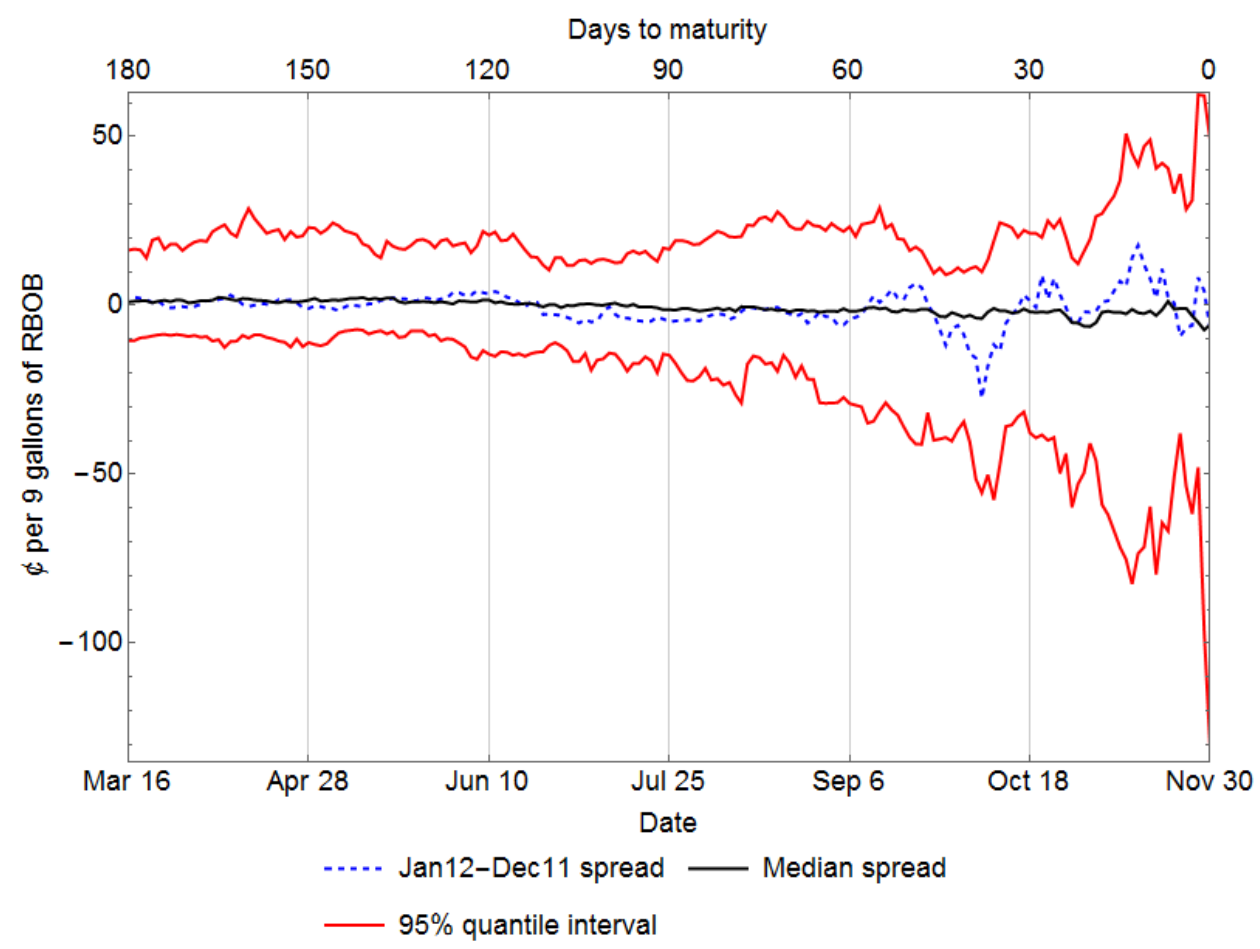

Figure 4: RBOB price spread for January 2012 - December 2011, controlling for oil prices, versus other one month calendar spreads, conditional on the same number of days to maturity 


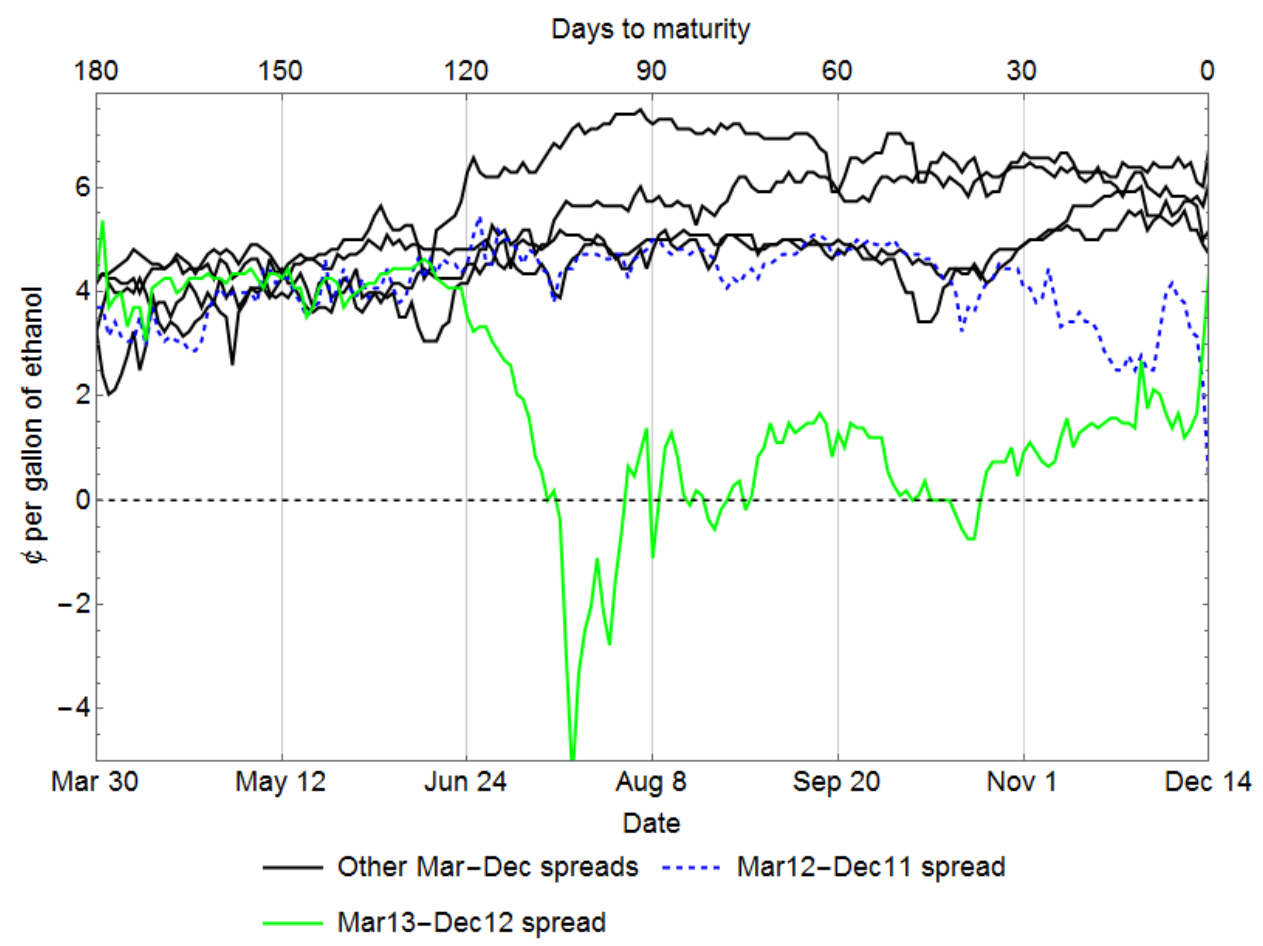

Figure 5: Corn price spreads for March - December 


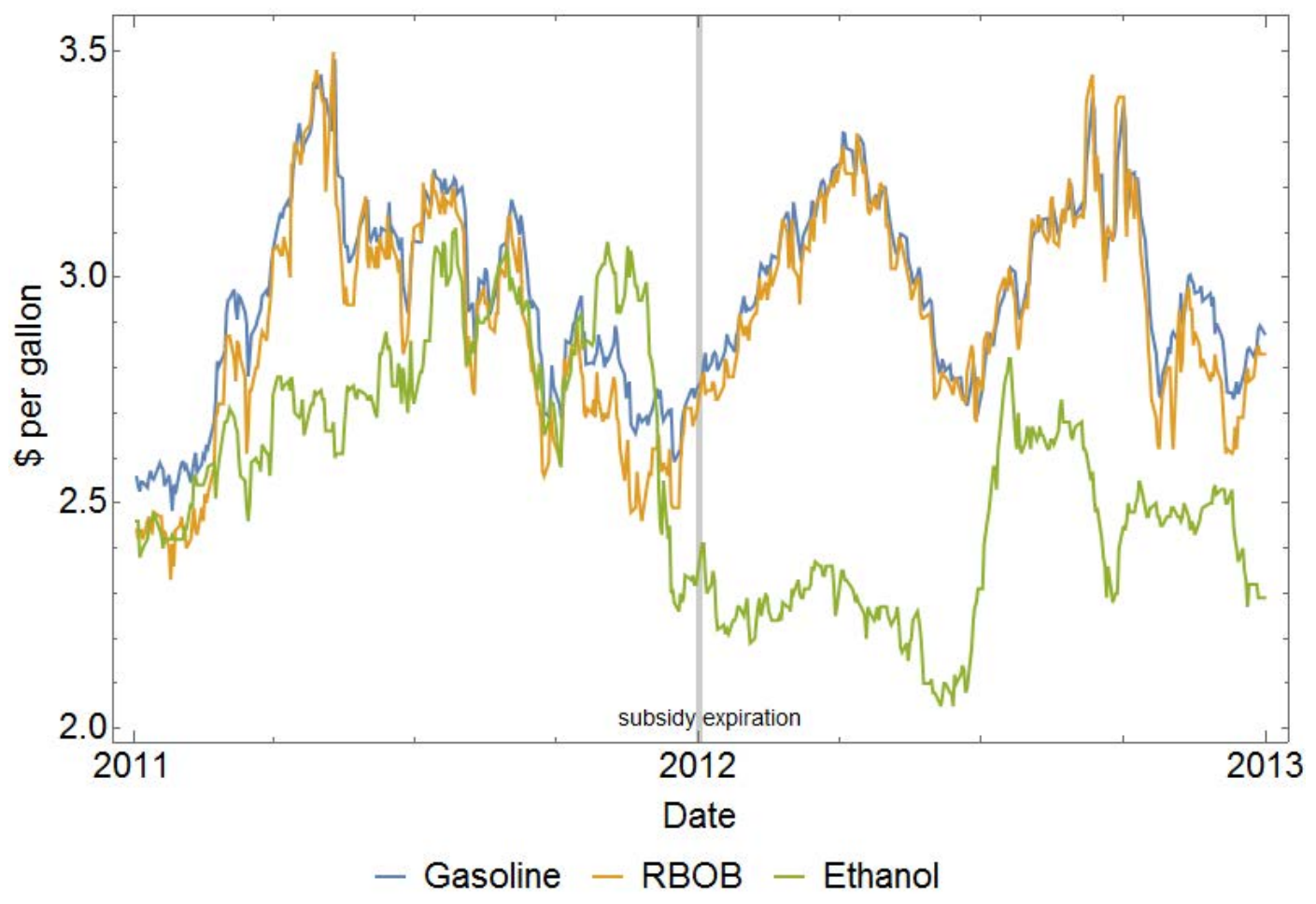

Figure 6: Daily prices for gasoline (E10), RBOB, and ethanol 


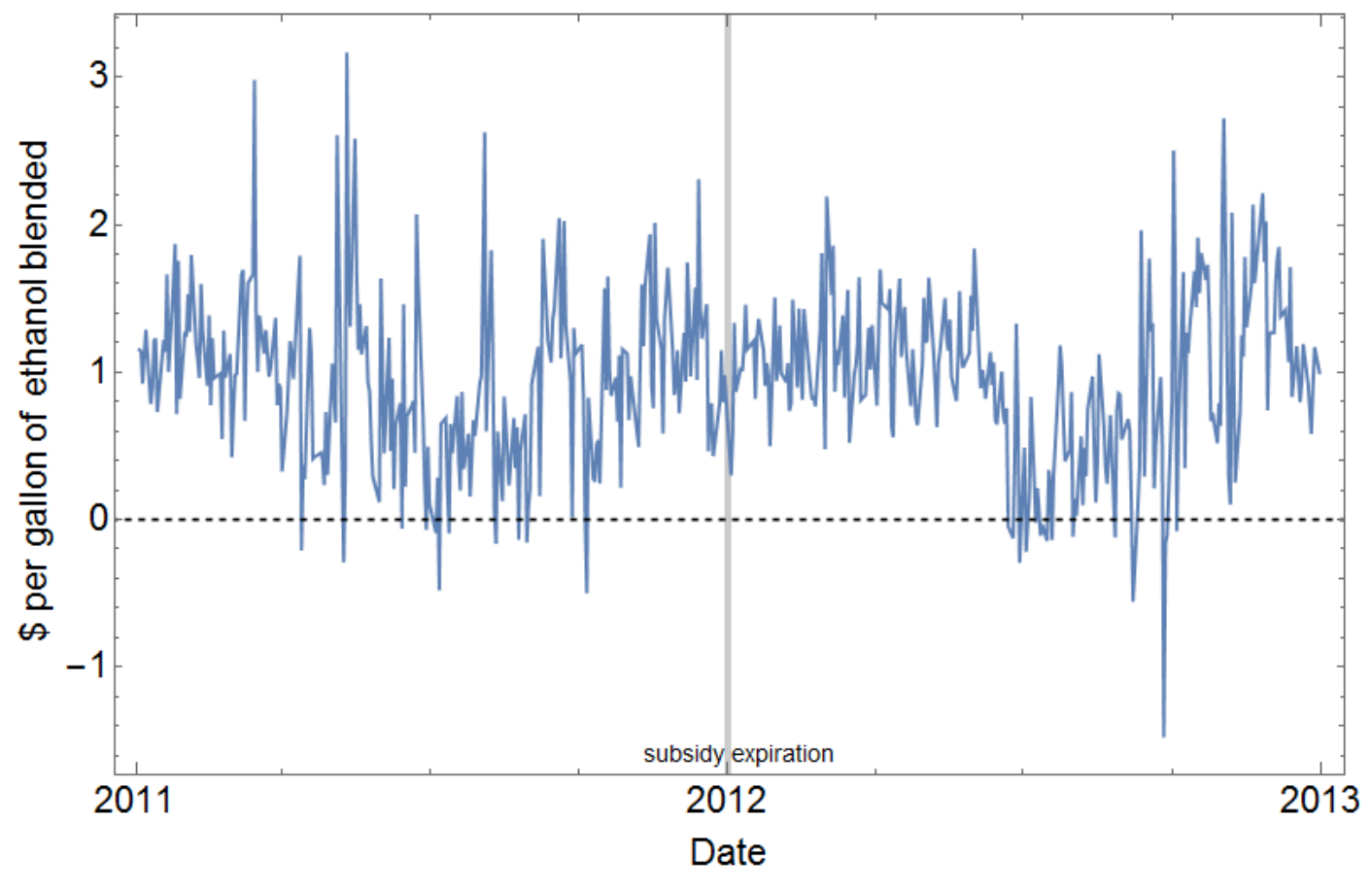

- Blender's Margin

Figure 7: Daily blender's margin 
Table 1: Commodity price and welfare impact of subsidy expiration, by stakeholder group

(1)

(3)

\begin{tabular}{|c|c|c|c|c|}
\hline & Stakeholders & Commodity produced & $\begin{array}{c}\text { Range of possible price } \\
\text { changes for commodity } \\
\text { produced }\end{array}$ & $\begin{array}{c}\text { Change in welfare based } \\
\text { on observed price changes } \\
\text { per gallon of ethanol }\end{array}$ \\
\hline$(1)$ & Ethanol producers & Ethanol & {$[-45 c, 0]$} & $\Delta P_{\text {ethanol }}-0.37 \Delta P_{\text {corn }}$ \\
\hline$(2)$ & Farmers & Corn & $\begin{array}{c}{\left[-2.7 \Delta P_{\text {ethanol }}, 0\right] \text { per }} \\
\text { bushel of corn }\end{array}$ & $0.37 \Delta P_{\text {corn }}$ \\
\hline$(3)$ & Oil refiners & $\mathrm{RBOB}$ & $\begin{array}{c}{[-5 \dot{c}, 0] \text { per gallon of }} \\
\text { RBOB }\end{array}$ & $9 \triangle P_{R B O B}$ \\
\hline$(4)$ & Blenders & Gasoline & $\begin{array}{l}{[0,4.5 \dot{c}] \text { per gallon of }} \\
\text { finished gasoline }\end{array}$ & $\begin{array}{c}10 \Delta P_{\text {gasoline }}-9 \Delta P_{R B O B}- \\
\Delta P_{\text {ethanol }}-45 \dot{c}\end{array}$ \\
\hline$(5)$ & Consumers & - & - & $-10 \Delta P_{\text {gasoline }}$ \\
\hline (6) & Total & - & - & $-45 \dot{c}$ \\
\hline
\end{tabular}

Notes: Welfare changes are per gallon of ethanol blended. All prices are in \$/per gallon (ethanol, RBOB, and gasoline) or bushel (corn). We assume a 1:9 ratio of ethanol to RBOB in each gallon of finished gasoline and 0.37 bushels of corn in each gallon of ethanol (see (1)). 
Table 2: Estimated commodity welfare impacts, by stakeholder group

\begin{tabular}{lcc}
\hline Stakeholders & Point estimate & $95 \%$ confidence interval \\
\hline Ethanol producers & $25 \dot{c}$ & {$[8 \dot{c}, 32 \dot{c}]$} \\
Farmers & $5 \dot{c}$ & {$[3 \dot{c}, 7 \dot{c}]^{\dagger}$} \\
Oil refiners & $0 \dot{c}$ & {$[0 \dot{c}, 45 \dot{c}]^{\ddagger}$} \\
Blenders & $15 \dot{c}$ & {$[0 \dot{c}, 35 \dot{c}]^{\ddagger}$} \\
Consumers & $0 \dot{c}$ & {$[0 \dot{c}, 45 \dot{c}]^{\ddagger}$} \\
\hline
\end{tabular}

Notes: All estimates are per gallon of ethanol blended. We assume a 1:9 ratio of ethanol to RBOB in each gallon of finished gasoline and 0.37 bushels of corn in each gallon of ethanol.

$\dagger$ Based on the standard deviation of four other comparable calendar spreads.

$\ddagger$ Based on the confidence interval for the effect on ethanol prices, $[-35 \dot{c},-15$ c $]$. 